\title{
GENERAL REVIEW
}

\section{THE hsp56 IMMUNOPHILIN COMPONENT OF STEROID RECEPTOR HETEROCOMPLEXES: COULD THIS BE THE ELUSIVE NUCLEAR LOCALIZATION SIGNAL-BINDING PROTEIN?}

\author{
William B. Pratt, * Michael J. Czar, louis F. Stancato and Janet K. Owens \\ The Department of Pharmacology, The University of Michigan Medical School, Ann Arbor, \\ MI 48109-0626, U.S.A
}

(Received 5 April 1993; accepted 6 May 1993)

\begin{abstract}
Summary-In many cells, the glucocorticoid receptor undergoes rapid steroid-mediated translocation from the cytoplasm to the nucleus, and this receptor is an excellent model for studying the mechanism of targeted protein movement through the cytoplasm. For such unidirectional movement to occur, the receptor must attach to a retrograde movement system in a manner that involves the nuclear localization signal. It is improbable that such attachment occurs via a direct protein-protein interaction between the receptor and the movement system; rather, one or more linker proteins are likely to be involved. As with other steroid receptors, the glucocorticoid receptor is associated with several other proteins in a heterocomplex. Two of these receptor-associated proteins are the heat shock proteins hsp90 and hsp56, and a third heat shock protein, hsp70, is required for assembly of the receptor heterocomplex. The hormone binding domain of the steroid receptors determines the interaction with both hsp 90 and hsp70. Hsp56 is known to bind to hsp90, but its potential site, or sites, of interaction with the receptor are undefined. Hsp56 has recently been cloned and demonstrated to be an immunophilin of the FK506/rapamycin binding class. The immunophilins have peptidyl-prolyl isomerase activity but their cellular functions are unknown. Herein, we review the literature on the hsp56 immunophilin component of the receptor heterocomplex and present a rationale for hsp56 being the protein that determines the direction of receptor movement via a direct protein-protein interaction with the nuclear localization signal.
\end{abstract}

\section{INTRODUCTION}

The steroid receptors are ligand-regulated transcription factors that alter expression from a limited number of genes. Thus, after their translation in the cytoplasm, these molecules must move to and subsequently within the nucleus in a precisely targeted manner. As originally shown by Picard and Yamamoto [1,2], nuclear localization is determined by positively charged nuclear localization signals (NLS) located in the receptors. The protein (or proteins) with which these NLS interact has not been defined and the mechanism of receptor trafficking is also undefined. It is known, however, that steroid receptors in cytosols and in intact cells are associated with several proteins, three of which are the heat

\footnotetext{
*To whom correspondence should be addressed.
}

shock proteins hsp90, hsp70 and hsp56 (see Refs [3-5] for review). In a cell-free translation system, it has been shown that the glucocorticoid receptor (GR) becomes associated with hsp90 at the termination of receptor translation [6]. It is well established that untransformed glucocorticoid receptors that are located either entirely within the cytoplasm or entirely within the nucleus can be recovered from cells in molybdate-containing cytosols in their heterocomplex form, and the heterocomplex is thought to be the form of the receptor that undergoes cytoplasmic-nuclear trafficking in the cell $[4,7]$. The functions of the various proteins in the receptor heterocomplex are poorly understood. Hsp90 is always present, it binds directly to the hormone binding domain of the receptor and it appears to remain tightly bound to the receptor during trafficking. Indirect evidence has suggested that hsp70 is required for the initial association of hsp90 
rabbit reticulocyte lysate was shown to be entirely dependent upon addition of purified hsp 70 [11]. No role for the hsp 56 component of the heterocomplex has been established. In this review, we briefly summarize the literature on hsp56, which is now known to be an immunophilin of the FK506/rapamycin binding class, and we explore the possibility that hsp 56 may be the protein that interacts directly with the nuclear localization signals of the steroid receptors.

\section{Hsp56 UP TO 1992}

\section{The ECI antibody}

Hsp 56 was discovered by Faber and his colleagues $[12,13]$ essentially at the same time that the steroid receptors were found to be associated with hsp90.* Nakao et al. [12] partially purified (10- to 30 -fold) the $9 \mathrm{~S}$ form of the unliganded progesterone receptor (PR) from rabbit uterine cytosol in buffers containing molybdate, which stabilizes the receptor in the heterocomplex form, and then used this preparation to raise a monoclonal antibody. The result was the production of the ECl IgG antibody, which was shown to shift the migration of rabbit PR on sucrose density gradient centrifugation [12]. The ECl monoclonal antibody bound to the $8.5 \mathrm{~S}$ nontransformed PR but not to smaller forms of the steroid binding protein [13]. The epitope for the ECl antibody was located on a $59 \mathrm{kDa}$ rabbit protein that Tai and Faber [13] proposed was part of the rabbit $\mathrm{PR}$ heterocomplex, in addition to an $\sim 92 \mathrm{kDa}$ protein that was subsequently identified as hsp90.

Further work by the Faber lab [14] demonstrated that the ECl antibody formed immune complexes with nontransformed rabbit estrogen, progestin, androgen, and glucocorticoid receptors, leading to the proposal that the $59 \mathrm{kDa}$ protein was a component of steroid receptor heterocomplexes in general. It was found that immobilized ECl immunoadsorbed both $59 \mathrm{kDa}$ and $92 \mathrm{kDa}$ proteins from cytosols prepared from several tissues. The two proteins were clearly distinct from one another and EC1

*It is only fair to note that this work was performed in 1982 , and because of the reluctance of reviewers to seriously consider the notion that cytosolic steroid receptors could be associated in a biologically meaningful way with other proteins, the association was considered to be an artifact and it was not published until early in 1985 . reacted directly only with p59. Tai et al. [14] proposed that $\mathrm{p} 59$ and the $92 \mathrm{kDa}$ protein were bound to each other.

Because the $\mathrm{ECl}$ antibody does not react with rat, chicken or mouse cytosolic protein [12], the most commonly used systems for molecular analysis of steroid receptor heterocomplexes, interest in the p59 did not disseminate rapidly to other laboratories. Although immunoadsorption of untransformed GR from $\mathrm{L}$ cell cytosol under low stringency wash conditions had identified a mouse $55 \mathrm{kDa}$ protein composed of several isomorphs that was coimmunoadsorbed with the receptor [15], it was only recently, when a broad spectrum antibody against p59 became available, that the two proteins were found to be the same [16]. Renoir et al. [17], however, found that $\mathrm{ECl}$ did recognize a protein in calf and human MCF breast cancer cell cytosols that was associated with PR, ER, AR and GR by sucrose gradient analysis. The receptor heterocomplexes could be stabilized by transition metal oxyanions (molybdate and tungstate) and by chemical cross-linking with dimethylpimelimidate. From the results of both $\mathrm{ECl}$ immunoaffinity purification and cross-linking experiments, Renoir et al. [17] proposed that p59 was bound to hsp90 and that it did not interact directly with the hormone binding subunit.

\section{The heat shock protein heterocomplex}

In 1990, we reported that the ECl antibody reacted with the untransformed GR in cytosol prepared from human IM-9 lymphocytes [18]. Upon analysis by two-dimensional gel electrophoresis, the human protein consisted of two major isomorphs migrating at $56 \mathrm{kDa}$ with minor forms migrating at $54 \mathrm{kDa}$, and we called the protein p56. The p56 was found to be of moderate abundance and, when it was immunoadsorbed from cytosol, both hsp90 and hsp70 as well as a small amount of a $23 \mathrm{kDa}$ protein were coimmunoadsorbed with it. About the same time, it was shown that both hsp70 and a $23 \mathrm{kDa}$ protein were immunoadsorbed with both PR and GR heterocomplexes from other systems ( [15, 19-21], see Refs [3-5] for reviews). This was the first indication, however, that a heterocomplex containing more than one heat shock protein existed in cytosols independent of the presence of steroid receptors [18]. N-terminal sequencing showed that p56 was a unique human protein [18]. Given that two major components of the heterocomplex were heat shock proteins, Sanchez [22] asked if the rate of 
synthesis of p56 increased in IM-9 cells submitted to heat shock or chemical stress (arsenite). He found that p56 was itself a heat shock protein, now calling it $h s p 56$.

The concept that these three heat shock proteins may exist together in a heterocomplex was confirmed independently by Perdew and Whitelaw [23] who immunoadsorbed hsp 90 from Hepa 1clc7 cytosol with a monoclonal antibody and found five major proteins of $\mathrm{M}_{\mathrm{r}}$ $68,000,63,000,56,000,50,000$ and 188,000 to be coimmunoadsorbed. The 68 and $56 \mathrm{kDa}$ proteins were identified as hsp70 and hsp56, respectively. The $50 \mathrm{kDa}$ protein was subsequently shown by Whitelaw et al. [24] to be the same $50 \mathrm{kDa}$ phosphoprotein that was reported in the early 1980s to be a component of the heterocomplex of pp60 $60^{v-s r c}$ with hsp90 (see Ref. [25] for review).

\section{Orientation of hsp56 in the receptor hetero- complex}

Although it is now clear that hsp56 binds directly to hsp90, it is an unresolved issue whether or not the hsp56 in the steroid receptor heterocomplex comes into direct contact with the steroid binding protein as well as with hsp90. In the proposal of Renoir et al. [17], hsp56 binds to hsp90 but not to the receptor itself. However, studies of GR-hsp 90 cross-linking argue that hsp56 comes into direct contact with the receptor. In 1988, Rexin et al. [26] treated both mouse lymphoma cytosol and intact cells with dimethyl suberimidate and then immunopurified the $\left[{ }^{3} \mathrm{H}\right]$ dexamethasone mesylate-labeled GR and resolved the cross-linked products by SDS-polyacrylamide gel electrophoresis. An analysis of the size of the crosslinked products revealed complexes consistent with a GR linked to two molecules of a $90 \mathrm{kDa}$ protein and one molecule of an $\sim 50 \mathrm{kDa}$ protein and subcombinations thereof (GR $+\mathrm{p} 50$, $\mathrm{GR}+\mathrm{p} 90, \mathrm{GR}+\mathrm{p} 50+\mathrm{p} 90, \mathrm{GR}+2 \mathrm{p} 90)$. Subsequently, the $\sim 50 \mathrm{kDa}$ protein cross-linked to the GR was shown to be hsp56 [27]. Both Rexin et al. [28] and Alexis et al. [29] have used the cross-linking approach to establish that hsp 56 is present in GR heterocomplexes in intact cells. In the model of Renoir et al. [17], it would follow that hsp 56 is cross-linked in the heterocomplex because it is cross-linked to hsp90, which in turn is cross-linked to the receptor. However, as Rexin et al. [27] have demonstrated on denaturing gels a cross-linked form of the GR which contains GR and hsp56 but not hsp90, it seems quite possible that the receptor and hsp56 may lie proximate to each other in the larger heterocomplex.

The recovery of small amounts of a GR-hsp56 cross-linked duplex leads us to consider the possibility of a direct protein-protein interaction between hsp 56 and the receptor. The question then becomes where is that interaction? It is quite clear that the hormone binding domain of the GR contains the sites of direct interaction with hsp90 (see Refs $[3,4,10]$ for review), and by itself, the hormone binding domain is sufficient for formation of the GR-hsp90 complex, both in the cell and under cell-free conditions [30]. Schowalter et al. [31] have shown that the hormone binding domain of the PR is necessary for binding of both hsp 90 and hsp70 [31]. At present, it is not known whether hsp56 also associates with the hormone binding domain or whether it may interact elsewhere on the receptor. Because Rexin et al. [26] have identified a cross-linked $\sim 95 \mathrm{kDa}$ product of the $\mathrm{nt}^{\mathrm{i}}$ mutant GR $\left(\mathrm{nt}^{\mathrm{i}}\right.$ $\mathrm{GR}+\sim 50 \mathrm{kDa}$ ), the $\mathrm{NH}_{2}$-terminal half of the receptor can be ruled out as a required site of contact. Below, we will consider the proposal that the NLS is the site for direct interaction of hsp56 with the receptor. First, however, we will briefly review the exciting new information regarding identification of hsp56 as an immunophilin.

\section{THE YEAR 1992 LEADS TO A MELDING OF THE FIELDS OF STEROID RECEPTOR AND IMMUNOPHILIN RESEARCH}

\section{Hsp56 is an immunophilin}

The immunophilins are proteins that bind immunosuppressive agents like cyclosporin A, FK506 and rapamycin in a high-affinity and specific manner. All of the members of this family have peptidyl-prolyl cis-trans isomerase (PPIase) activity in vitro, and it is thought that the immunophilins, like the hsp70 and hsp90 components of the heterocomplex, play major fundamental roles in protein folding and trafficking in the cell (see Refs $[32,33]$ for reviews). FK506 binds to the PPIase site on the immunophilin and inhibits the isomerase activity. Several immunophilins in the FKBP (FK506 Binding Protein) family have been identified by SDS-polyacrylamide gel electrophoresis following affinity chromatography of mammalian cell extracts over FK506- and rapamycin-Affigel-10 matrices. 
The initial observation relating to hsp 56 was made when Fretz et al. [34] passed human Jurkat cell extracts over matrices of immobilized FK506 or rapamycin and demonstrated that several proteins could be specifically eluted with competing soluble drug. Other than the abundant $12 \mathrm{kDa}$ immunophilin (FKBP-12), the major species eluted from the affinity matrix was an $\sim 60 \mathrm{kDa}$ protein. This $60 \mathrm{kDa}$ protein was then shown by Yem et al. [35] to possess the $\mathrm{NH}_{2}$ terminal sequence we had published for human hsp56 [18], and to possess sequence homologies to a region near the $\mathrm{COOH}$-terminus of FKBP12 and FKBP-13. Tai et al. [36] demonstrated that the $59 \mathrm{kDa}$ protein isolated from human IM-9 lymphocyte cytosol with their FK506Affigel matrix reacted with the ECl antibody against hsp56 and had the same $\mathrm{NH}_{2}$-terminal sequence as hsp56. In a different approach, Wiederrecht et al. [37] purified a $\left[{ }^{3} \mathrm{H}\right]$ dihydroFK506 binding activity from human Jurkat cells, isolating a $51 \mathrm{kDa}$ protein that by sequence analysis of peptides suggested strong similarity or identity with hsp56. Thus, by mid 1992 , it was clearly established that hsp 56 is an immunophilin of the FK 506/rapamycin binding class.

An important observation was made by Tai et al. [36] who showed that their FK506-Affigel matrix coisolated hsp 90 and hsp 70 from IM-9 cell cytosol. This confirmed by a second method the existence of the heat shock protein heterocomplex that we had previously identified in the same cytosol by coimmunoadsorption with the ECl antibody [18] and that Perdew and Whitelaw [23] had identified in Hepa 1c1c7 cytosol by coimmunoadsorption with the 8D3 monoclonal antibody against hsp90. Tai et al. [36] also showed that the GR was coisolated by the FK 506 affinity matrix when molybdate was present to stabilize binding of the receptor to hsp90.

\section{Cloning of hsp 56}

In work that was published at the same time as the FK506 affinity matrix identification of hsp56, Lebeau et al. [38] used the EC1 antibody to screen a rabbit liver cDNA library and clone the rabbit protein. The cloned cDNA coded for an open reading frame of 458 amino acids containing a segment between amino acids 41 and 134 of the protein that had $55 \%$ amino acid homology to the PPIase FKBP-12. As noted by Tai et al. [36], all 10 amino acids in the FK506 binding site of FKBP-12 were conserved in the rabbit p59. Screening of the rabbit p59 for consensus sequences revealed possible phosphorylation sites, a putative ATP-binding site, and a consensus calmodulin-binding site [38].

Peattie et al. [39] cloned the human protein, which had a calculated $M_{r}$ of 51,810 and called it hFKBP52. The protein was expressed in Escherichia coli, purified, and demonstrated to have PPIase activity inhibited by FK506. Northern analysis demonstrated expression in human heart, brain, placenta, lung, liver, skeletal muscle, kidney, pancreas and lymphocytes. This broad distribution is consistent with the widely accepted view that the immunophilins play critical roles in basic cellular functions.

\section{Predicted structure of hsp 56}

Callebaut et al. [40] have used sequence alignment analysis and hydrophobic cluster analysis to predict a three domain structure for the rabbit protein. They have chosen to call the protein HBI, which stands for "hsp binding immunophilin". The first predicted domain (amino acids 32-138) at the $\mathrm{NH}_{2}$-terminus has the homology with FKBP-12 noted above, with a predicted PPIase calalytic site, which includes the conserved FK506 binding domain. The second predicted domain (149-253) has $34 \%$ identity with the first domain, but 8 of 13 amino acids critical for FK506 binding are not conserved. The third predicted domain (268-372) has lost all FKBP homology and is followed by an 86 amino acid tail to the $\mathrm{COOH}$-terminus (458), which contains the consensus calmodulin binding site. The three predicted globular domains are separated by two hydrophilic regions, with the hinge between domains I and II being highly acidic.

\section{Terminology}

As the reader is by now aware, multiple laboratories have adopted individual terms referring to the same protein, including $\mathrm{p} 59[17]$, p56 [18], hsp56 [22], FKBP59 [36], FKBP51 [37], FKBP52 [39], and HBI [40]. The protein has a predicted molecular weight from sequence of $\sim 52,000 \mathrm{da}$, and on SDS-polyacrylamide gels, a range of $M_{r}$ from $51-60 \mathrm{kDa}$ have been reported. As the protein exists in a heteroprotein complex with hsp90 and hsp $70[18,23,36]$ and as it has itself been reported to be a heat shock protein [22], it would seem important to retain its designation as an hsp. As with other hsps (e.g. hsp90, hsp70) it would seem reasonable to use a representative $M_{r}$ on denaturing gel 
electrophoresis (e.g. hsp56) rather than the calculated $\mathbf{M}_{\mathbf{r}}$ for an individual species (e.g. hsp52, human).

From the perspective of someone investigating the binding and action of FK506, the term FKBP is useful and differentiates the protein from those that bind cyclosporin A. However, within the context of biology in general, the heat shock phenomenon is widely recognized and the importance of the hsps in basic cellular functions is widely accepted. Thus, we suggest that hsp 56 or hsp 56 immunophilin be used as generic terms for this protein so that its relationship to the heat shock response can be appreciated and, most importantly, so that biologists working in heat shock will become informed about the work proceeding in the laboratories focusing on immunosuppression. The introduction of new appelations like HBI for "hsp binding immunophilin" seems counterproductive in the broader context.

Other immunophilins identified in receptor complexes

In addition to hsp90, hsp70 and p23, the chicken PR heterocomplex contains 50 and $54 \mathrm{kDa}$ proteins that have now been characterized as members of the FKBP family [41]. Six peptide sequences from $\mathrm{p} 50$ have $80 \%$ identity with regions of rabbit hsp56, and p50 reacts with the UPJ56 antibody against hsp56 (David Smith, personal communication). Seven peptides from p54 have $60 \%$ identity with rabbit hsp56 [41].

The fields of immunophilin and steroid receptor research meet in another recent unexpected observation. An estrogen-derivatized affinity resin was reported in 1990 to isolate estrogen receptor from calf uterine cytosol in association with hsp90 and $\sim 40$ and $22 \mathrm{kDa}$ proteins [42]. Ratajczak et al. [43] have now cloned and sequenced the $40 \mathrm{kDa}$ protein. This protein, which they called estrogen receptor binding cyclophilin (ERBC), contains a COOH-terminal domain with significant sequence homology to an internal region of hsp56. A putative calmodulin binding site is located at the extreme $\mathrm{COOH}$-terminus. This $40 \mathrm{kDa}$ receptor-associated protein is apparently the same as a $40 \mathrm{kDa}$ cyclosporin A-binding protein, CyP-40, recently purified from bovine brain by the Handschumacher laboratory [44]. Amino acid sequences for six CyP-40 peptides showed complete identity with corresponding sequences in the $40 \mathrm{kDa}$ receptor-associated protein [43].

\section{SPECULATIONS REGARDING THE FUNCTION OF hsp56 IN THE STEROID RECEPTOR HETEROCOMPLEX}

Potential functions for hsp56 in steroid hormone action

The three heat shock proteins present in steroid receptor heterocomplexes are protein folding enzymes--hsp70 has well documented protein folding/unfolding activity (see Ref. [45] for review), hsp 90 has been reported to chaperone the folding of certain proteins by preventing their self-aggregation in vitro $[46,47]$, and hsp 56 is a PPIase. Members of both the FKBP class of PPIase (hsp56) and the cyclophilin class of PPIase have now been reported to bind to hsp90 [48]. This might suggest that, under some conditions, hsp90 and PPIases act together in a spatially and temporally coordinated manner as a protein folding enzyme complex. It does not seem, however, that the PPIase activity of hsp56 is required for folding events involved in formation of the GR heterocomplex. We have shown that reticulocyte lysate-mediated assembly of the immunopurified mouse receptor into a fully competent steroid binding heterocomplex with hsp90 is accompanied by association of the receptor with rabbit hsp56 [16]. However, FK506 does not affect either native or cell-free assembly of the GR heterocomplex, demonstrating that hsp56 PPIase activity is not required for the assembly process [16].

We have also found that FK506 treatment of L929 cells containing the pMMTV-CAT reporter plasmid (LMCAT cells) does not induce CAT gene expression or modify either receptor translocation or enhancement of gene expression caused by $1 \mu \mathrm{M}$ dexamethasone [16]. However, it was subsequently found by Ning and Sanchez [49] that, when low concentrations of dexamethasone $\left(10^{-8} \mathrm{M}\right)$ were present in the culture medium, high concentrations $\left(10^{-6}-10^{-5} \mathrm{M}\right)$ of $\mathrm{FK} 506$ or rapamycin potentiated both GR translocation and GR-mediated CAT gene expression in the LMCAT cells. It was the impression of Ning and Sanchez [49] that potentiation of transcriptional activation was due to increased GR translocation, an effect that is not seen at high concentrations of dexamethasone at which all of the steroid binding sites on the receptor are occupied. These observations of Ning and Sanchez [49] could reflect an ability of FK506 to shift the receptor to a higher affinity conformation for dexamethasone binding, and thus, they might not reflect an 
effect of FK506 on the process of receptor translocation itself. Unfortunately, the effect of FK 506 or rapamycin on GR affinity for steroid in the intact cell was not determined. The FK 506 potentiation of dexamethasone-induced CAT gene expression does suggest, however, that hsp56 plays a role somewhere in receptor function. At the moment, there is no evidence for an effect of hsp56 on receptor folding and heterocomplex assembly, but receptor trafficking from the cytoplasm to the nucleus is a poorly understood process where hsp56 may play a role.

\section{Receptor trafficking}

It is well established that movement of particles occurs in cytoplasm and axoplasm in a bidirectional manner along microtubule scaffolds, and it has been suggested that steroid receptors may move along such systems while in their heterocomplex state (see Ref. [7] for review). Both hsp90 [50,51] and hsp56 [52] have been localized by immunofluorescence to filamentous cytoplasmic structures distributing in microtubular fashion in several types of cells, a distribution that would be consistent with a role in protein movement.

Shuttling of steroid receptors both into and out of the nucleus in intact cells has recently been demonstrated by the laboratories of Milgrom [53] and DeFranco [54]. There is evidence consistent with the proposal that such shuttle trafficking occurs along microtubule-based tracts. For example, immunofluorescence studies utilizing monospecific monoclonal antibodies have localized cytoplasmic glucocorticoid receptors to fibrillar cytoskeletal structures $[55,56]$ that have been shown to colocalize with microtubules in human gingival fibroblasts [57]. In a more dynamic example, Barsony et al. [58] have used a recently developed technique based on microwave fixation to demonstrate the rapid (occurring within 1-3 min) calcitriol-initiated movement of vitamin $\mathrm{D}$ receptors from the cytoplasm to the nucleus in cultured human fibroblasts. The first event was clumping of receptors, which occurred 15-45 s after hormone addition, followed by alignment of clumps along cytoplasmic fibrils within $30-45 \mathrm{~s}$, which in turn was followed by perinuclear accumulation of clumps within 45-90 s [58]. The fibrils with which the vitamin $D$ receptors associate, and presumably the scaffold upon which movement occurs, have been identified as microtubules [59].

\section{The concept of a transportosome}

The proposal that protein movement may occur within the cytoplasm while a protein is in association with hsp90 is not new. A decade ago, it was proposed that $\mathrm{pp} 60^{\text {p-src }}$ is bound to hsp90 while undergoing trafficking through the cytoplasm to the plasma membrane (see Ref. [25] for review). This proposal was based on labeling studies where it was shown that pp $60^{r-s r c}$ was bound to hsp90 as soon as it was translated and remained associated with the heat shock protein until it was localized at the plasma cell membrane via its $\mathrm{NH}_{2}$-terminal myristic acid. While it undergoes this journey, pp60 $0^{v-s r c}$ also appears to be associated with a $50 \mathrm{kDa}$ protein that can be phosphorylated by pp60 $0^{v-s r c}$ itself [25] and is clearly an hsp90-associated protein [24]. We have recently shown that rabbit reticulocyte lysate can form a complex of pp60 $60^{r-s r c}$ with hsp90, hsp70 and p50 under the same conditions it forms the GR heterocomplex [60]. The native and the reconstituted pp $60^{i-s r c}$ heterocomplex is stabilized by transition metal oxyanions, such as molybdate, in the same manner as the GR heterocomplex [61]. This is perhaps not surprising, as molybdate is now known to bind to hsp90 and to produce a conformational change in the hsp [62] that stabilizes its interactions with other proteins.

The heterocomplex story as it has developed with the GR is in many ways similar to that of pp $60^{i-s r c}$ For example, we have shown in the reticulocyte lysate system that the GR becomes associated with hsp90 at the termination of receptor translation [6] and it is clear that unliganded glucocorticoid receptors that are located entirely in the cytoplasm of the intact cell by immunofluorescence (e.g. L cells [63]) are recovered in cytosol in association with both hsp90 and hsp56 ([16], see Refs [3,10] for review). It is also clear that untransformed mouse GR stably expressed in CHO cells is located entirely within the nucleus (indeed throughout all planes of the nucleus [64]) and that the receptor is recovered in cytosol in association with both hsp90 [21] and hsp56 [65]. The work of the Gehring [28] and Alexis [29] labs has made it clear that the GR is associated with both hsp 90 and hsp56 in intact cells. Taken together, these observations lead us to conclude that the GR binds to these proteins essentially concomitantly with receptor translation and remains associated with them while they 
undergo trafficking through the cytoplasm to the nucleus and subsequently while they traffic within the nucleus.

The receptor trafficking model being tested in our laboratory has been detailed elsewhere $[4,7]$. The essential feature is that hsp90 and hsp56, probably together with other proteins, such as p23, become associated with steroid receptors by a mechanism that requires the protein unfoldase activity of hsp70[11]. The heat shock protein heterocomplex (with or without the continued presence of hsp70) would then act as a transport complex for the receptor. Thus, we propose that, in the cytoplasm (as shown for other cellular compartments) protein transport and protein folding are linked processes $[4,7]$. We have coined the word transportosome to refer to this protein transport complex.

\section{Do many proteins form trafficking complexes with hsp90?}

The notion is that steroid and dioxin receptors and $\mathrm{pp} 60^{v-s r c}$ and some other oncogenic avian protein tyrosine kinases bind to the hsp90 component of the transportosome with unusually high avidity, and that other proteins may form comparatively weak native trafficking complexes with hsp90 that have missed detection by conventional biochemical and immunological approaches. As a model protein to test this notion, we chose c-Raf, a serine/threonine kinase that undergoes trafficking to the plasma membrane where it is under tight control by growth factor receptors. We found that Raf forms a native complex with both hsp90 and p50 in transfected cells and that, like the GR heterocomplex, this complex is formed by the reticulocyte lysate protein folding system [65]. The complex of hsp 90 with Raf is weaker than that with pp60 $60^{v-s r c}$ or steroid receptors, but it is formed in the same way and is also stabilized by molybdate.

The concept that hsp90 may be bound to many proteins undergoing trafficking reflects an important change in the thinking about receptor-heat shock protein complexes. It is established that members of the hsp70 family bind cotranslationally with a wide variety of proteins [66]. Both the promiscuous ability of hsp70 to bind to many newly translated proteins with very different structures and the requirement of hsp70 for formation of steroid receptor-hsp90 complexes are consistent with the notion that hsp90 may be complexed, albeit more weakly, with multiple proteins and perhaps play a role in their trafficking within the cell.

If hsp90 must be bound to the GR while it is transported through the cytoplasm to the nucleus, then the glucocorticoid-mediated transformation event that permits GR translocation to the nucleus cannot result in dissociation of the receptor from hsp90. For the past several years, we have assumed that, upon transformation, the GR dissociates from hsp90 and other proteins in the heterocomplex. We have assumed this because the transformed receptor is no longer in the 9S form (and hsp90 is not coimmunoadsorbed with receptor) in cytosols prepared from cells that were exposed to steroid (see Ref. [67] for review). Also, a similar apparent glucocorticoid-mediated dissociation of GR from hsp90 occurs under cell-free conditions in cytosols [68-70]. Although we have assumed that the receptor dissociates from hsp 90 , the steroid-transformed GR may still be in a weak complex with hsp90 that does not survive our traditional gradient centrifugation and coimmunoadsorption detection methods. In other words, when the receptor is transformed, it may be converted from the high affinity complex that is unique to the untransformed steroid receptors and pp60 $60^{r-s r c}$ to a weaker interaction, such as the complex that has been detected by modified methods with Raf [65] and is perhaps typical of hsp90 interaction with multiple other proteins.

\section{Does hsp56 determine the direction of receptor movement?}

After transformation by steroid, the GR moves rapidly to the nucleus under the direction of the NLS [1]. If, as we think, the receptor remains associated with the heat shock protein complex, a protein in the complex may determine the direction of movement by attaching the transport particle to the microtubule/dynein system that determines movement in the retrograde direction toward the nucleus. The attachment of the receptor to the movement system may require more than one protein in the heterocomplex, but one protein in this attachment system must interact directly with the NLS. On the basis of analysis of primary structure and known protein-protein interactions in the heat shock protein heterocomplex, we suggest that hsp56 is the NLS-binding protein.

Our model is summarized in Fig. 1. Nuclear localization signals are composed of concentrations of positively charged amino acids (see 


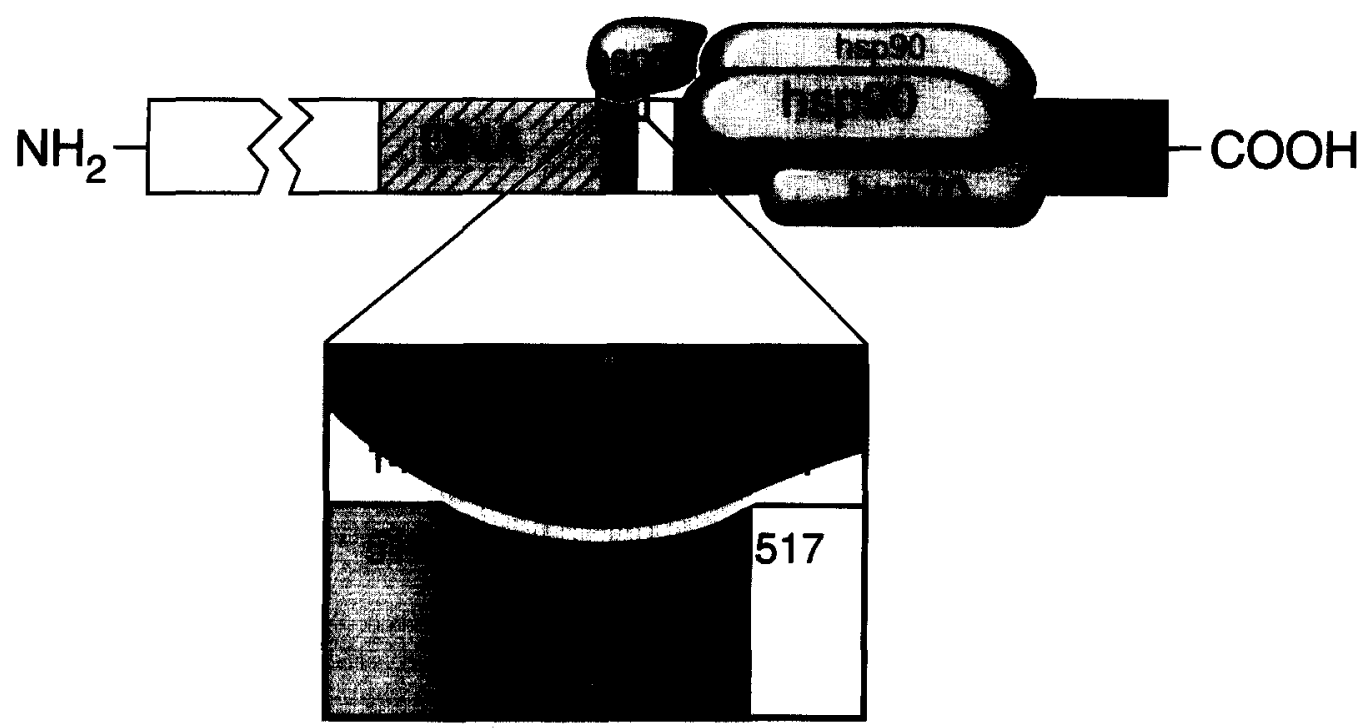

Fig. 1. Model of the heat shock protein complex bound to the GR. Only the COOH-terminal half of the GR is presented, with three domains indicated as follows: DNA binding domain (hatch marks), nuclear localization signal (closed), HBD domain (stippled). As described in the text, hsp90 binds as a dimer to the HBD domain. Formation of the receptor heterocomplex requires hsp $70[8,9,11]$, which is known to bind to the HBD of PR [31] and ER [30]. Hsp70 is not recovered with GR that are cytoplasmic [21, 27, 29], and it may dissociate when the heterocomplex is completely formed [11]. Hsp56 is shown with two contact sites in the complex - a direct interaction with hsp90 $[14,17,18]$ and a postulated interaction of its highly negatively charged first hinge region with the nuclear localization signal of the receptor. In this case, we have presented the NL1 of the rat GR [1]. The numbers in the blowup section of this postulated direct GR-hsp56 binding site identify the $\mathrm{NH}_{2}$-terminal and $\mathrm{COOH}$-terminal amino acids in the hinge region of rabbit hsp56 [40] and the rat GR NL1 [1].

Ref. [71] for review) and in the primary sequence for the NL1 of the rat GR [1] shown in Fig. 1, 6 out of 8 consecutive amino acids are positively charged. This predicts a proteinprotein interaction through a domain in the NLS-binding protein that is highly acidic. As mentioned above, the short hinge segment between the first and second globular domains predicted by Callebaut et al. [40] is highly acidic. This hinge segment (Glu-Asp-Leu-ThrAsp-Asp-Glu-Asp) of rabbit hsp56 shown in Fig. 1 contains 6 out of 8 amino acids that are negatively charged [40], and this segment is retained with two conservative replacements (Glu-Asp-Leu-Thr-Glu-Glu-Glu-Asp) between amino acids 140-147 in human hsp56 (hFKBP52) [39].

This model in which hsp56 interacts both with the receptor and hsp90 could explain an observation made with the estrogen receptor (ER) that is inconsistent with observations made with the GR and the PR. Chambraud et al. [72] have reported that both the hormone binding domain (HBD) of the ER and a segment at the $\mathrm{COOH}$ terminal extremity of the DNA binding domain, which corresponds to the NLS [2], are required for detection of the 9S form of the ER. Neither the HBD alone nor the NLS alone was sufficient for recovery of transfected mutant ERs as 9S [72]. This differs from the GR, where it is clear that the HBD without the NLS forms a stable complex with hsp90 [30]. The results with the ER have led to a widely accepted model proposing that hsp90 itself must interact directly with both the HBD and the NLS regions of steroid receptors [73]. We have used the modified technique we employed to detect the Raf-hsp90 complex to demonstrate both native and cell-free reconstituted complexes of hsp90 with the HE14 segment of the human ER, which contains only the HBD [30]. Thus, the HBD of the ER is sufficient for a weak complex with hsp90 but the complex does not survive detection using the gradient centrifugation technique. It is easy to see how these observations are explained by the model of Fig. 1. Although hsp90 itself may form a relatively weak complex with the ER HBD, in the receptor heterocomplex hsp90 is bound to hsp56, which in turn contacts the NLS. Neither hsp interaction with the receptor might be sufficient to yield a detectible 9S complex for the wild-type ER, but the two together would yield a 9S complex, as observed by Chambraud et al. [72]. 
There is, as yet, no direct evidence that hsp56 forms a protein-protein contact with the NLS. It is interesting to note, however, that hsp56 has been found in association with steroid receptors, all of which must proceed in a retrograde direction to the nucleus and localize there in a manner that is dependent upon the presence of the NLS [1, 2]. In the case of pp60 $60^{\text {ossc }}$ and Raf, the direction of trafficking is towards their sites of action at the inside of the plasma membrane, and their heterocomplex form contains $\mathrm{p} 50$ but not hsp56 [65]. It is interesting that p50 is not present in the GR heterocomplex [24]. Finally, it is worth noting that two proteins that specifically bind the large $T$ antigen NLS have been purified and shown to promote nuclear import in a permeabilized cell system [74]. No sequence information is yet available, but the proteins migrate on denaturing gels at 56 and $54 \mathrm{kDa}$.

Acknowledgements - The authors' investigations were supported by NIH Grants CA28010 and DK 31573.

\section{REFERENCES}

1. Picard D. and Yamamoto K. R.: Two signals mediate hormone-dependent nuclear localization of the glucocorticoid receptor. EMBO Jl 6 (1987) 3333-3340.

2. Picard D., Kumar V., Chambon P. and Yamamoto K. R.: Signal transduction by steroid hormones: nuclear localization is differentially regulated in estrogen and glucocorticoid receptors. Cell Reg. 1 (1990) 219-299.

3. Pratt W. B.: Interaction of hsp 90 with steroid receptors: organizing some diverse observations and presenting the newest concepts. Molec. Cell. Endocr. 74 (1990) C69-C76.

4. Pratt W. B., Hutchison K. A. and Scherrer L. C. Steroid receptor folding by heat shock proteins and composition of the receptor heterocomplex. Trends Endocr. Metab. 3 (1992) 326-333.

5. Smith D. F. and Toft D. O.: Steroid receptors and their associated proteins. Molec. Endocr. 7 (1993) 4-11.

6. Dalman F. C., Bresnick E. H., Patel P. D., Perdew G. H., Watson S. J. and Pratt W. B.: Direct evidence that the glucocorticoid receptor binds to hsp90 at or near the termination of receptor translation in vitro. J. Biol. Chem. 264 (1989) 19815-19821.

7. Pratt W. B.: Control of steroid receptor function and cytoplasmic-nuclear transport by heat shock proteins. BioEssays 14 (1992) 841-847.

8. Smith D. F., Stensgard B. A., Welch W. J. and Toft D. O.: Assembly of progesterone receptor with heat shock proteins and receptor activation are ATP mediated events. J. Biol. Chem. 267 (1992) 1350-1356.

9. Hutchison K. A., Czar M. J., Scherrer L. C. and Pratt W. B.: Monovalent cation selectivity for ATP-dependent association of the glucocorticoid receptor with hsp70 and hsp90. J. Biol. Chem. 267 (1992) 14047-14053.

10. Pratt W. B., Scherrer L. C., Hutchison K. A. and Dalman F. C.: A model of glucocorticoid receptor unfolding and stabilization by a heat shock protein complex. J. Steroid Biochem. Molec. Biol. 41 (1992) 223-229.

11. Hutchison K. A., Dittmar K. and Pratt W. B.: Proof that hsp70 is required for assembly of the glucocorticoid receptor into a heterocomplex with hsp 90 . Submitted manuscript.

12. Nakao K., Myers J. E. and Faber L. E.: Development of a monoclonal antibody to the rabbit 8.5S uterine progestin receptor. Can.J. Biochem. Cell Biol. 63 (1985) 33-40.

13. Tai P. K. and Faber L. E.: Isolation of dissimilar components of the $8.5 \mathrm{~S}$ nonactivated uterine progesterone receptor. Can. J. Biochem. Cell Biol. 63 (1985) 41-49.

14. Tai P. K., Maeda Y., Nakao K., Wakim N. G., Duhring J. L. and Faber L. E.: A $59 \mathrm{kDa}$ protein associated with progestin, estrogen, androgen, and glucocorticoid receptors. Biochemistry 25 (1986) 5269-5275.

15. Bresnick E. H., Dalman F. C. and Pratt W. B.: Direct stoichiometric evidence that the untransformed $M_{r}$ $300,000,9 \mathrm{~S}$ glucocorticoid receptor is core unit derived from a larger heteromeric complex. Biochemistry 29 (1990) 520-527.

16. Hutchison K. A., Scherrer L. C., Czar M. J., Ning, Y., Sanchez E. R., Leach K. L., Deibel M. R. and Pratt W. B.: FK506 binding to the 56-kilodalton immunophilin (hsp56) in the glucocorticoid receptor heterocomplex has no effect on receptor folding or function. Biochemistry 32 (1993) 3953-3957.

17. Renoir J. M., Radanyi C., Faber L. E. and Baulieu E. E.: The non-DNA-binding heterooligomeric form of mammalian steroid hormone receptors contains a hsp90-bound 59-kilodalton protein. J. Biol. Chem. 265 (1990) 10740-10745.

18. Sanchez E. R., Faber L. E., Henzel W. J. and Pratt W. B.: The 56-59-kilodalton protein identified in untransformed steroid receptor complexes is a unique protein that exists in cytosol in a complex with both the 70 - and 90-kilodalton heat shock proteins. Biochemistry 29 (1990) 5145-5152.

19. Kost S. L., Smith D., Sullivan W., Welch W. J. and Toft D. O.: Binding of heat shock proteins to the avian progesterone receptor. Molec. Cell. Biol. 9 (1989) 3829-3838.

20. Smith D. F., Faber L. E. and Toft D. O.: Purification of unactivated progesterone receptor and identification of novel receptor-associated proteins. J. Biol. Chem. 265 (1990) 3996-4003.

21. Sanchez E. R., Hirst M., Scherrer L. C., Tang H. Y., Welsh M. J., Harmon J. M., Simons S. S., Ringold G. M. and Pratt W. B.: Hormone-free glucocorticoid receptors overexpressed in Chinese hamster ovary cells are localized to the nucleus and are associated with both hsp70 and hsp90. J. Biol. Chem. 265 (1990) 20123-20130.

22. Sanchez E. R.: Hsp56: a novel heat shock protein associated with untranformed steroid receptor complexes. J. Biol. Chem. 265 (1990) 22067-22070.

23. Perdew G. H. and Whitelaw M. L.: Evidence that the 90-kDa heat shock protein (hsp90) exists in cytosol in heteromeric complexes containing hsp70 and three other proteins with $M_{r}$ of $63,000,56,000$, and 50,000 . J. Biol. Chem. 266 (1991) 6708-6713.

24. Whitelaw M. L., Hutchison K. and Perdew G. H.: A $50 \mathrm{kDa}$ cytosolic protein complexed with hsp90 is the same protein complexed with $\mathrm{pp} 60^{\mathrm{w}-\mathrm{sc}} / \mathrm{hsp} 90$ in cells transformed by the Rous sarcoma virus. J. Biol. Chem. 266 (1991) 16436-16440.

25. Brugge J. S.: Interaction of the Rous sarcoma virus protein $\mathrm{pp} 60^{\mathrm{src}}$ with the cellular proteins $\mathrm{pp} 50$ and $\mathrm{pp} 90$. Curr. Topics Microbiol. Immun. 123 (1986) 1-22.

26. Rexin M., Busch W., Segnitz B. and Gehring U.: Tetrameric structure of the nonactivated glucocorticoid receptor in cell extracts and intact cells. FEBS Lett. 241 (1988) 234-238.

27. Rexin M., Busch W. and Gehring U.: Protein components of the nonactivated glucocorticoid receptor. J. Biol. Chem. 266 (1991) 24601-24605. 
28. Rexin M., Busch W., Segnitz B. and Gehring U.: Structure of the glucocorticoid receptor in intact cells in the absence of hormone. J. Biol. Chem. 267 (1992) 9619-9621.

29. Alexis M. N., Marridou I. and Mitsiou D. J.: Subunit composition of the untransformed glucocorticoid receptor in the cytosol and in the cell. Eur. J. Biochem. 204 (1992) 75-84.

30. Scherrer L. C., Picard D., Massa E., Harmon J. M., Simons S. S., Yamamoto K. R. and Pratt W. B.: Evidence that the hormone binding domain of steroid receptors confers hormonal control on chimaeric proteins by determining their hormone-regulated binding to hsp90. Biochemistry 32 (1993) 5381-5386.

31. Schowalter D. B., Sullivan W. P., Maihle N. J., Dobson A. D. W., Conneely O. M., O'Malley B. W. and Toft D. O.: Characterization of progesterone receptor binding to the 90 - and $70-\mathrm{kDa}$ heat shock proteins. J. Biol. Chem. 266 (1991) 21165-21173.

32. Schreiber S. L.: Chemistry and biology of the immunophilins and their immunosuppressive ligands. Science 251 (1991) 283-287.

33. Walsh C. T., Zydowski L. D. and McKeon F. D.: Cyclosporin $\mathbf{A}$, the cyclophilin class of peptidylprolyl isomerases, and blockade of $\mathrm{T}$ cell signal transduction. J. Biol. Chem. 267 (1992) 13115-13118.

34. Fretz H., Albers M. W., Galat A., Standaert R. F., Lane W. S., Burakoff S. J., Bierer B. E. and Schreiber S. L.: Rapamycin and FK506 binding proteins (immunophilins). J. Am. Chem. Soc. 113 (1991) 1409-1411.

35. Yem A. W., Tomasselli A. G., Heinrikson R. L., Zurcher-Neely H., Ruff V. A., Johnson R. A. and Deibel M. R.: The hsp56 component of steroid receptor complexes binds to immobilized FK506 and shows homology to FKBP-12 and FKBP-13. J. Biol. Chem. 267 (1992) 2868-2871.

36. Tai P. K., Albers M. W., Chang H., Faber L. E. and Schreiber S. L.: Association of a 59-kilodalton immunophilin with the glucocorticoid receptor complex. Science 256 (1992) 1315-1318.

37. Wiederrecht G., Hung S., Chan H. K., Marcy A., Martin M., Calaycay J., Boulton D., Sigal N., Kincaid R. L. and Siekierka J. J.: Characterization of high molecular weight FK-506 binding activities reveals a novel FK-506-binding protein as well as a protein complex. J. Biol. Chem. 267 (1992) 21753-21760.

38. Lebeau M. C., Massol N., Herrick J., Faber L. E., Renoir J. M., Radanyi C. and Baulieu E. E.: P59, an hsp90-binding protein. $J$. Biol. Chem. 267 (1992) $4281-4284$.

39. Peattie D. A., Harding M. W., Fleming M. A., DeCenzo M. T., Lipke J. A., Livingston D. J. and Benasutti M.: Expression and characterization of human FKBP52, an immunophilin that associates with the $90-\mathrm{kDa}$ heat shock protein and is a component of steroid receptor complexes. Proc. Natn. Acad. Sci. U.S.A. 89 (1992) 10974-10978.

40. Callebaut I., Renoir J. M., Lebeau M. C., Massol N., Burny A., Baulieu E. E. and Mornon J. P.: An immunophilin that binds $M_{r} 90,000$ heat shock protein: main structural features of a mammalian p 59 protein. Proc. Natn. Acad. Sci. U.S.A. 89 (1992) 6270-6274.

41. Smith D. F., Baggenstoss B. A., Marion T. N. and Rimerman R. A.: A highly conserved FKBP and a novel FKBP-related protein are components of progesterone receptor complexes. J. Biol. Chem. 268 (1993) In press.

42. Ratajczak T., Hlaing J., Brockway M. J. and Hähnel R.: Isolation of untransformed bovine estrogen receptor without molybdate stabilization. J. Steroid Biochem. 35 (1990) 543-553.

43. Ratajczak T., Carrello A., Mark P. J., Warner B. J., Simpson R. J., Moritz R. L. and House A. K.: The cyclophilin component of the unactivated estrogen receptor contains a TPR domain and shares identity with p59 (FK BP59) J. Biol. Chem. 268 (1993) In press

44. Kieffer L. J., Thalhammer T. and Handschumacher R. E.: Isolation and characterization of a $40-\mathrm{kDa}$ cyclophilin-related protein. J. Biol. Chem. 267 (1992) 5503-5507.

45. Rothman J. E.: Polypeptide chain binding proteins: catalysts of protein folding and related processes in cells. Cell 59 (1989) 591-601.

46. Miyata $Y$. and Yahara I.: The $90-\mathrm{kDa}$ heat shock protein, hsp90, binds and prevents casein kinase II from self-aggregation and enhances its kinase activity. J. Biol. Chem. 267 (1992) 7042-7047.

47. Wiech H., Buchner J., Zimmermann R. and Jakob U.: Hsp90 chaperones protein folding in vitro. Nature 358 (1992) 169-170.

48. Nadeau K., Das A. and Walsh C. T.: Hsp90 chaperonins possess ATPase activity and bind heat shock transcription factors and peptidyl prolyl isomerases. J. Biol. Chem. 268 (1993) 1479-1487.

49. Ning Y. M. and Sanchez E. R.: Potentiation of glucocorticoid receptor-mediated gene expression by the immunophilin ligands FK 506 and rapamycin. J. Biol. Chem. 268 (1993) 6073-6076

50. Sanchez E. R., Redmond T., Scherrer L. C., Bresnick E. H., Welsh M. J. and Pratt W. B.: Evidence that the 90-kilodalton heat shock protein is associated with tubulin-containing complexes in $\mathrm{L}$ cell cytosol and in intact PtK cells. Molec. Endocr. 2 (1988) 756-760

51. Redmond T., Sanchez E. R., Bresnick E. H., Schlesinger M. J., Toft D. O., Pratt W. B. and Welsh M. J.: Immunofluorescence colocalization of the $90-\mathrm{kDa}$ heat shock protein and microtubules in interphase and mitotic mammalian cells. Eur. J. Cell. Biol. 50 (1989) $60-75$.

52. Ruff V. A., Yem A. W., Munns P. L., Adams L. D. Reardon I. M., Deibel M. R. and Leach K. L.: Tissue distribution and cellular localization of hsp56, an FK506-binding protein. J. Biol. Chem. 267 (1992) 21285-21288

53. Guiochon-Mantel A., Lescop P., Christin-Maitre S. Loosfeld H., Perrot-Applanat $M$. and Milgrom E. Nucleocytoplasmic shuttling of the progesterone receptor. EMBO Jl 10 (1991) 3851-3859.

54. Chandran V. R, and DeFranco D. B.: Internuclear migration of chicken progesterone receptor, but not SV40 large tumor antigen, in transient heterokaryons. Molec. Endocr. 6 (1992) 837-844.

55. Wikstrom A. C., Bakke O., Okret S., Bronnegard M. and Gustafsson J. A.: Intracellular localization of the glucocorticoid receptor: evidence for cytoplasmic and nuclear localization. Endocrinology 120 (1987) 1232-1242.

56. Akner G., Sundqvist K. G., Denis M., Wikstrom A. C and Gustafsson J. A.: Immunocytochemical localization of glucocorticoid receptor in human gingival fibroblasts and evidence for a colocalization of glucocorticoid receptor with cytoplasmic microtubules. Eur. J. Cell. Biol. 53 (1990) 390-401.

57. Akner G., Mossberg K., Wikstrom A. C., Sundqvist K. G. and Gustafsson J. A.: Evidence for colocalization of glucocorticoid receptor with cytoplasmic microtubules in human gingival fibroblasts, using two different monoclonal anti-GR antibodies, confocal laser scanning microscopy and image analysis. J. Steroid Biochem. Molec. Biol. 39 (1991) 419-421.

58. Barsony J., Pike J. W., DeLuca H. F. and Marx S. J. Immunocytology with microwave-fixed fibroblasts shows $1 \alpha, 25$-dihydroxyvitamin $\mathrm{D}_{3}$-dependent rapid and estrogen-dependent slow reorganization of vitamin $\mathrm{D}$ receptors. J. Cell Biol. 111 (1990) 2385-2395. 
59. Barsony J. and McKoy W.: Molybdate increases intracellular 3',5'-guanosine cyclic monophosphate and stabilizes vitamin D receptor association with tubulincontaining filaments. J. Biol. Chem. 267 (1992) 24457-24465.

60. Hutchison K. A., Brott B. K., De Leon J. H., Perdew G. H., Jove R. and Pratt W. B.: Reconstitution of the multiprotein complex of pp60 $0^{\mathrm{src}}$ hsp90, and p50 in a cell-free system. J. Biol. Chem. 267 (1992) 2902-2908.

61. Hutchison K. A., Stancato L. F., Jove R. and Pratt W. B.: The protein-protein complex between $\mathrm{pp} 60^{v-s r c}$ and hsp90 is stabilized by molybdate, vanadate, tungstate and an endogenous cytosolic metal. J. Biol. Chem. 267 (1992) 13952-13957.

62. Csermely P., Kajtar J., Hollosi M., Jalsovszky G., Holly S., Kahn C. R., Gergely P., Soti C., Mihaly K. and Somogyi J.: ATP induces a conformational change of the $90-\mathrm{kDa}$ heat shock protein (hsp90). J. Biol. Chem. 268 (1993) 1901-1907.

63. Hsu S., Qi M. and DeFranco D. B.: Cell cycle regulation of glucocorticoid receptor function. EMBO $\mathrm{Jl} 11$ (1992) 3457-3468.

64. Martins V. R., Pratt W. B., Terracio L., Hirst M. A., Ringold G. M. and Housley P. R.: Demonstration by confocal microscopy that unliganded overexpressed glucocorticoid receptors are distributed in a nonrandom manner throughout all planes of the nucleus. Molec. Endocr. 5 (1991) 217-225.

65. Stancato L. F., Chow Y. H., Hutchison K. A., Perdew G. H., Jove R. and Pratt W. B.: Raf exists in a native heterocomplex with hsp 90 and p50 that can be reconstituted in a cell-free system. J. Biol. Chem. In press.

66. Beckman R. P., Mizzen L. A. and Welch W. J.: Interaction of hsp70 with newly synthesized proteins: implications for protein folding and assembly. Science 248 (1990) 850-854.

67. Pratt W. B.: Transformation of glucocorticoid and progesterone receptors to the DNA-binding state J. Cell. Biochem. 35 (1987) 51-68.
68. Sanchez E. R., Meshinchi S., Tienrungroj W. Schlesinger M. J., Toft D. O. and Pratt W. B.: Relationship of the $90-\mathrm{kDa}$ murine heat shock protein to the untransformed and transformed states of the $\mathrm{L}$ cell glucocorticoid receptor. J. Biol. Chem. 262 (1987) 6986-6991

69. Denis M., Poellinger L., Wikstrom A. C. and Gustafsson J. A.: Requirement of hormone for thermal conversion of the glucocorticoid receptor to a DNA-binding state. Nature 333 (1988) 686-688.

70. Meshinchi S., Sanchez E. R., Martell K. J. and Pratt W. B.: Elimination and reconstitution of the requirement for hormone in promoting temperature-dependent transformation of cytosolic glucocorticoid receptors to the DNA-binding state. J. Biol. Chem. 265 (1990) 4863-4870.

71. Diingwall C. and Laskey R. A.: Nuclear targeting sequences-a consensus? TIBS 16 (1991) 478-481.

72. Chambraud B., Berry M., Redeuilh G., Chambon P. and Baulieu E. E.: Several regions of human estrogen receptor are involved in the formation of receptor-heat shock protein 90 complexes. J. Biol. Chem. 263 (1990) 20686-20691.

73. Baulieu E. E., Binart N., Cadepond F., Catelli M. G., Chambraud B., Garnier J. M., Gasc G., Groyer-Schweizer G., Oblin M. E., Radanyi C., Redeuilh G., Renoir J. M. and Sabbah M.: Do receptor-associated nuclear proteins explain earliest steps of steroid hormone function? In The Steroid/Thyroid Hormone Receptor Family and Gene Regulation. Proc. Ind Int. CBT Symp. Stockholm, Sweden, Nov. 1988 (Edited by J. Carlstedt-Duke, H. Eriksson and J. A. Gustafsson). Birkäuser Verlag, Berlin (1989) pp. 301-318.

74. Adam S. A. and Gerace L.: Cytosolic proteins that specifically bind nuclear localization signals are receptors for nuclear import. Cell 66 (1991) 837-847. 